\title{
Special issue of the journal international communication of Chinese culture: religion and philosophy-Introduction
}

\author{
Jana S. Rošker ${ }^{1}$
}

Published online: 12 November 2020

(C) Academy for International Communication of Chinese Culture 2020

Confucianism, Daoism and Buddhism are often regarded as the three ideational foundations of traditional Chinese society. As philosophies or religions, they had a great influence not only on the thinking and spirituality of the Chinese people, but also on their government, social structure, science and arts. Even though their particular teachings and beliefs sometimes contradicted each other, there was still enough room for their overlapping and influencing each other. This special issue of the journal International Communication of Chinese Culture aims to help international readers understand the inimitable exchange between these three ideational traditions and to provide an insight into their specific roles and functions within ancient, but also modern and contemporary Chinese society.

The texts collected in this special issue are divided into four related content areas or sections. Each of these sections contains several articles that are linked to their respective topics.

The first section deals with political philosophy and contains two articles related to this research area. It begins with Huang Chun-chieh's contribution, which focuses on East Asian discourses and interpretations of the classical Chinese political thinker Guan Zhong, in particular his views on the Confucian concept of humaneness (ren); through comparative analysis, the author shows how Guan Zhong's humaneness (has been interpreted in socio-political environments of individual East Asian countries, revealing some innovative aspects of Confucian ethics derived from these intercultural interactions. The other article in this section is Dai Zhicheng's Connotation of National Identity und Contemporary Appeal unter Political Confucianism, in which the author explains the Confucian identity of belonging. In this context, the essay follows the assumption that the concept of national identity can be used as a tool for

Jana S. Rošker

jana.rosker@ff.uni-lj.si

1 University of Ljubljana, Ljubljana, Slovenia 
democratization when applied within the framework of a rational political philosophy such as Confucianism.

The second scope of contents is related to philosophical and religious dialogues in the context of the Chinese tradition of ideas. This section contains four articles, namely Jana S. Rošker's The Debate at the Spring of Heaven and the Fusion of Confucianism and Chan-Buddhism in Neoconfucian Epistemology, Selusi Ambroggio's The first Dispute between Jesuits and Buddhists in China, and André Bueno's Confucius, a Chinese Prophet? The translation of Chinese classics by Joaquim Guerra and the religious dialogue in the twentieth century. While in her article, Jana S. Rošker analyses some possible parallels between Confucianism and Chan Buddhism which can be detected in the famous Debate at the Spring of Heaven between Qian Dehong and Wang Ji, the two most famous followers of Confucianism Wang Yangming, Selusi Ambroggio is dealing with a more intercultural debate, namely that between Buddhism and Christianity. The latter religion is also the main subject of the last article in this section, namely André Bueno's paper on the translation and interpretation of the original Confucianism by the Christian priest Joachim Guerra, written in the 1970s. The fourth and last article in this section was written by Steven Marsh and deals with Daoist philosophy through the lens of Ye Hai-yen's interpretation of Zhuangzi's philosophy of life.

The topic of the next section refers to Chinese logic or the methodology of Chinese philosophy. In his essay entitled From Mohism to the School of Names, from Pragmatism to Materialist Dialectics: Gongsun Longzi as a Text and Source of Chinese Logic 1920-1937, Jan Vrhovski provided a concise and well-founded general overview of the development of the interpretation of Gongsun Longzi the abovementioned period. Among other topics, the author attempts to uncover some of the key indicators and reasons for the reappearance and new developments of these interpretations during the period under research. This article is followed by Lee Hsien-chung's essay Using 'Thought Units' to Apply the Method of Creative Hermeneutics, in which the author proposes a new method of analysis and interpretation of classical and traditional Chinese philosophy. Lee calls this method "the method of thought units". This method is based on Charles Wei-Hsün Fu's so-called "creative hermeneutics", but develops and improves it by giving it the necessary context construction. Using several concrete examples in which he utilizes the method of thought units, Lee's contribution shows how the interpretation method of creative hermeneutics can be applied to contemporary research.

The last section deals with various topics from the field of modern and contemporary Chinese philosophy. In the first contribution of this section John Zijiang Ding provides a new interpretation of the theoretical system of Li Zehou, who is undoubtedly one of the most influential Chinese philosophers of our time. The author examines the East-West synthetism or integrationism of Li Zehou from the perspective of Li's "Threefold Philosophy", his" "Post-Marxist Anthropological Ontology", and his "Transformation and reconceptualization of Confucianism". This essay is followed by two articles dealing with two representatives of Modern New Confucianism. Joseph Ciaodo critically points out some hitherto little known aspects of the work of Tang Junyi, who is one of the most famous representatives of the so-called 2nd generation of Modern New Confucianism. Through a meticulous analysis of Tang's 
Gospel of Love, the author seeks to show that the very problem of love can reveal some difficulties inherent in the formulation of a genuine global philosophical discourse on any subject. The last—but by no means the least important-treatise in this special issue is Ady van den Stock's Liang Shuming's 'China: the Country of Reason (1967-1970): Revolution, Religion and Ethnicity in the Reinvention of the Confucian Tradition. The author examines some hitherto unknown aspects of the philosophy of Liang Shuming, who was a member of the first generation of Modern New Confucianism. Through a critical and in-depth interpretation of Liang's China: the Country of Reason, van den Stock reveals some complex relationships between revolutionary, religious and ethnic identities in the late philosophy of this early Modern Confucian scholar.

Despite their diverse topics and points of view, the articles collected in this issue clearly show that many ideas and values from traditional Chinese philosophies and religions still prevail in today's China, as they have been incorporated into many aspects of people's lives. Understanding these ideas and their complex backgrounds will therefore certainly improve our understanding of Chinese society and culture.

Jana S. Rošker, guest editor

Acknowledgements The papers in this special were collected and edited during the author's visiting research at the Institute for International Communication of Chinese Studies at the Beijing Normal University. The guest editor would like to express her gratitude to this institution, and, of course, especially to its wonderful members, for their all-encompassing support of her research work. The guest editor also acknowledges the support of the Slovenian Research Agency (ARRS) in the framework of the research core funding Asian Languages and Cultures (P6-0243) and in the scope of the research project N6-0161 (Complementary scheme) Humanism in Intercultural Perspective: Europe and China. 